\title{
Relatedness of Antibodies to Peptides Containing Homocitrulline or Citrulline in Patients with Rheumatoid Arthritis
}

\author{
Patrick Lac, Maud Racapé, Lillian Barra, David A. Bell, and Ewa Cairns
}

\begin{abstract}
Objective. Antibodies that target citrullinated protein/peptide (ACPA) and homocitrullinated/carbamylated protein/peptide (AHCPA) are associated with rheumatoid arthritis (RA). The relationship between ACPA and AHCPA remains unclear. We examined the expression and cross-reactivity of these antibodies using citrulline- and homocitrulline-containing synthetic peptides, CitJED and HomoCitJED, respectively, which have equal numbers of citrulline or homocitrulline residues on the same peptide backbone.

Methods. Serum from healthy subjects $(\mathrm{n}=51)$ and patients with RA $(\mathrm{n}=137)$, systemic lupus erythematosus (SLE; $\mathrm{n}=37$ ), and psoriatic arthritis (PsA; $\mathrm{n}=37$ ) were screened for IgG anti-CitJED and anti-HomoCitJED antibodies by ELISA. Cross-reactivity of these antibodies was examined by inhibition with various concentrations of CitJED and HomoCitJED.

Results. Out of 137 patients with RA, antibodies to CitJED and HomoCitJED were detected in 69 $(50 \%)$ and 78 (57\%), respectively. Anti-CitJED and HomoCitJED antibodies were $77 \%$ concordant and their levels were strongly correlated [Spearman correlation coefficient $\left(\mathrm{r}_{\mathrm{s}}\right)=0.6676$ ]. Sera from 25/27 patients (93\%) with RA were inhibited by both CitJED and HomoCitJED with equal or higher affinity for the cognate (homologous) peptide.

Conclusion. Antibodies to CitJED and HomoCitJED frequently occurred in RA, but were not found in SLE or PsA, suggesting that these antibodies are specific to RA. Cross-reactivity between anti-HomoCitJED and anti-CitJED antibodies suggests that ACPA and AHCPA are derived from the same B cell population and both may contribute to the pathogenesis of RA. (First Release December 1 2017; J Rheumatol 2018;45:302-9; doi:10.3899/jrheum.170446)
\end{abstract}

Key Indexing Terms: ANTICYCLIC CITRULLINATED ANTIBODIES AUTOIMMUNE DISEASES ELISA

\section{AUTOANTIBODIES} RHEUMATOID ARTHRITIS
Rheumatoid arthritis (RA) is an inflammatory autoimmune disorder that predominantly affects the joints and is specifically associated with anticitrullinated protein antibodies (ACPA) $)^{1,2,3,4}$. Recently, antihomocitrullinated protein/peptide

From the Department of Microbiology and Immunology, and the Department of Medicine/Rheumatology, The University of Western Ontario, London, Ontario, Canada.

Funded by a grant (\#133685) from The Canadian Institutes of Health Research to E. Cairns, D.A. Bell, and L. Barra. E. Cairns is supported by an award from The Calder Foundation. P. Lac has been supported by a Frederick Banting and Charles Best Canada Graduate Scholarship-Master's from the Canadian Institutes of Health Research.

P. Lac, BSc, Department of Microbiology and Immunology, The University of Western Ontario; M. Racapé, PhD, Paris Descartes University and Hôpital Necker, AP-HP, Paris, France; L. Barra, MD, Department of Microbiology and Immunology, and Department of Medicine/ Rheumatology, The University of Western Ontario; D.A. Bell, MD, Department of Medicine/Rheumatology, The University of Western Ontario; E. Cairns, PhD, Department of Microbiology and Immunology, and Department of Medicine/Rheumatology, The University of Western Ontario.

Address correspondence to Dr. E. Cairns, Department of Microbiology and Immunology, Schulich School of Medicine and Dentistry, The University of Western Ontario, Dental Sciences Building, Rm. 3014, London, Ontario N6A 5C1, Canada.E-mail: ewa.cairns@schulich.uwo.ca

Accepted for publication September 12, 2017. antibodies (AHCPA), also known as anticarbamylated protein antibodies (anti-CarP), have been identified in patients with $\mathrm{RA}^{5,6,7,8,9}$. Both ACPA and AHCPA can appear prior to disease onset ${ }^{6,10,11}$ and are predictive of more severe disease $^{8,12}$. ACPA have been demonstrated to be arthritogenic $^{13,14}$; the role of AHCPA in RA pathogenesis is unknown.

ACPA and AHCPA target citrullinated and homocitrullinated antigens, which arise from the posttranslational modification of arginine and lysine, respectively. Citrulline and homocitrulline have identical chemical structures, except homocitrulline has 1 additional carbon ${ }^{15}$. Studies show that ACPA can detect proteins containing homocitrulline $e^{5,16}$. However, the degree of cross-reactivity of ACPA for homocitrullinated proteins varied between the studies. These discrepancies may be a result of proteins having different numbers and locations of citrulline and homocitrulline, as we have previously reported for fibrinogen ${ }^{5}$, potentially resulting in different peptide antigens. Studies using citrulline- and homocitrulline-containing peptides with the same backbone were inconclusive because the affinity of antibodies to citrullinated and homocitrullinated peptides was not investigated ${ }^{17,18,19}$. 
In our study, we used a synthetic citrulline-rich peptide, JED (referred to here as CitJED), and its homocitrullinated counterpart (HomoCitJED). These peptides have a high proportion of citrulline or homocitrulline residues $(9 / 18)$, rendering immune reactivity to the backbone unlikely. Although not derived from an endogenously expressed autoantigen, we showed that CitJED detects clinically relevant antibody reactivities from patients with RA (anticyclic citrullinated peptide and anticitrullinated fibrinogen antibodies) $)^{5}$. Here we used CitJED and HomoCitJED to examine the expression, relatedness, and relative affinity of antibodies to citrullinated and homocitrullinated peptides in patients with RA.

\section{MATERIALS AND METHODS}

Study population. Serum samples were collected from healthy subjects and from patients with RA attending a tertiary care rheumatology clinic at St. Joseph's Health Care London (SJHC; London, Ontario, Canada). All patients with RA ( $n=137)$ satisfied the American College of Rheumatology (ACR) 2010 criteria for $\mathrm{RA}^{20}$, and all were treated with disease-modifying antirheumatic drugs. The swollen joint count in RA was determined by the treating rheumatologist, who performed a 64-joint examination; only swollen joints attributed to active RA were included in the count. RA patients without joint swelling were considered to be in remission. Demographic, serological, and clinical characteristics of patients with RA are summarized in Table 1. Healthy subject serum samples $(n=51)$ were collected from accompanying individuals who were unrelated to the patients with RA, and from staff members at SJHC or The University of Western Ontario. Healthy subjects were $65 \%$ female with a median age of 45 years (range 21-74). Healthy subjects did not have autoimmune disease and were excluded from the study if they had a history of joint symptoms.

Patients with systemic lupus erythematosus (SLE) and psoriatic arthritis (PsA) were previously described ${ }^{5}$. SLE patient serum samples were collected from patients attending SJHC $(n=37)$. All of these patients satisfied the ACR criteria for $\mathrm{SLE}^{21}$. Patients with SLE were $89 \%$ female with a mean age of 53 years (range 24-81). Of the 37 patients with SLE, 2 also had inflammatory arthritis and 1 had secondary Sjögren syndrome. PsA patient sera were collected from SJHC $(n=10)$ or were provided by Dr. Dafna Gladman from the Centre for Prognosis Studies in the Rheumatic Diseases, Toronto Western Hospital $(n=27)$, all of whom either met the ClASsification for Psoriatic ARthritis (CASPAR) criteria for PsA ${ }^{22}$ or were diagnosed as having PsA by

Table 1. Demographic, serological and clinical characteristics of patients with RA. Values are n (\%) or median (range) unless otherwise specified.

Patient Characteristics $\quad n=137$

Demographic features

Female

$100(73)$

Age, yrs

$59(19-82)$

Disease duration, yrs

$\operatorname{IgG}$ anti-CCP2-positive

$4(0.17-51)$

Concentration, units $/ \mathrm{ml}$

$87(64)$

RF-positive

$121.3(6.0-475.0)$

Smoking history ${ }^{\mathrm{a}}$

$83(61)$

$81(61)$

Joint swelling ${ }^{\mathrm{b}}$

$57(47)$

Average number of swollen joints

7.2

aData available for 132 patients with RA; ${ }^{\mathrm{b}}$ data available for 121 patients with RA. Joint swelling was determined by the treating rheumatologist and was associated with active RA disease activity. Anti-CCP: anticyclic citrullinated peptide antibodies; IgG: immunoglobulin G; RF: rheumatoid factor. a rheumatologist in a specialized PsA clinic. Patients with PsA were $46 \%$ female with a mean age of 53 years (range 36-82). Our study was approved by the Human Ethics Committee of The University of Western Ontario, according to the Declaration of Helsinki (REB \#09684E and \#100868).

Antigens. The following peptide antigens were used for antibody assays: (i) JED, referred to here as CitJED, a proprietary synthetic, cyclic peptide, 18 amino acids in length with 9 residues of citrulline $e^{5,23,24}$; (ii) homocitrullinated JED (HomoCitJED), identical to CitJED except that all 9 citrulline residues were replaced with homocitrulline. The sequences of both peptides were confirmed by mass spectrometry and the purity was $>85 \%$, as provided by the supplier.

CitJED and HomoCitJED were synthesized by Creative Peptides. CitJED and HomoCitJED were dissolved in 15\% hydrochloric acid (HCL) in sterile distilled water for direct ELISA and for inhibition ELISA. HomoCitJED was dissolved in 15\% HCL in sterile distilled water to increase its solubility. Although water soluble, CitJED was also dissolved in 15\% HCL to compare the antibody-binding properties of CitJED and HomoCitJED. This treatment did not alter peptide structure as determined by mass spectrometry and ELISA (data available upon request).

Antibody assays. Human sera were tested for expression of IgG anti-CitJED and IgG anti-HomoCitJED using direct antibody-binding ELISA. The protocol was adapted from Hill, et $a l^{4}$. Wells of ELISA plates (Nunc MaxiSorp, VWR) were coated overnight at $4^{\circ} \mathrm{C}$ with $2 \mu \mathrm{g}$ of peptide $(20$ $\mu \mathrm{g} / \mathrm{ml}$; CitJED or HomoCitJED) per well in carbonate coating buffer, $\mathrm{pH}$ 9.6. The wells were washed with wash buffer [phosphate buffered saline (PBS), $0.05 \%$ Tween] and blocked for $30 \mathrm{~min}$ at room temperature (RT) with $200 \mu \mathrm{l}$ of PBS [0.1\% bovine serum albumin (BSA)]. Serum samples were diluted $\geq 1: 100$ in diluent (PBS, 0.1\% BSA, 0.05\% Tween). Diluted sera $(100 \mu \mathrm{l})$ were added to duplicate wells and incubated for $30 \mathrm{~min}$ at RT. After washing, $100 \mu \mathrm{l}$ of biotin-conjugated goat anti-human IgG (1:8000; Sigma) and streptavidin horseradish peroxidase polymer (1:4000; Abcam) were added for $30 \mathrm{~min}$ at RT. After washing again, $100 \mu \mathrm{l}$ of $3,3^{\prime}, 5,5^{\prime}$-Tetramethylbenzidine substrate (Sigma) was added to the wells and incubated for $10 \mathrm{~min}$ at RT. The reaction was stopped with $50 \mu \mathrm{l}$ of $1 \mathrm{M} \mathrm{H}_{2} \mathrm{SO}_{4}$ and the absorbance was determined at $450 \mathrm{~nm}$.

Anti-CitJED and anti-HomoCitJED antibody concentrations in tested serum samples were determined by comparison to a reference serum sample, which was positive for both antibodies. These concentrations were quantified in arbitrary units/ml (AU/ml). The cutoff values for positive anti-CitJED and anti-HomoCitJED expression were $3.8 \mathrm{AU} / \mathrm{ml}$ and $25.3 \mathrm{AU} / \mathrm{ml}$, respectively. The cutoff values represent the mean antibody concentration of healthy subjects +2 SD. Anti-CitJED and anti-HomoCitJED concentrations are reported as an average of at least 3 repeat determinations $(<20 \%$ interassay variation). The number of patients with antibody levels $>2$ times the upper limit of normal were also reported, similar to ACR criteria ${ }^{20}$. IgG anticyclic citrullinated peptide antibodies (anti-CCP) 2 and IgM rheumatoid factor (RF) concentrations were determined by Pathology and Laboratory Medicine, London Health Sciences Centre or by our laboratory using anti-CCP2 (Euroimmun) or RF (Inova Diagnostics) ELISA kits

Cross-reactivity of anti-CitJED and anti-HomoCitJED was determined by inhibition ELISA. The protocol was adapted from Scinocca, et $a l^{5}$. Various amounts of soluble peptide in diluent were incubated with diluted RA patient sera for $1 \mathrm{~h}$ at RT prior to addition to ELISA wells coated with CitJED or HomoCitJED and carried out as described for direct antibody-binding ELISA. Inhibition assays were repeated at least twice for each patient. Sera were selected for inhibition ELISA based on antibody concentration, which were a minimum of $10 \mathrm{AU} / \mathrm{ml}$ for anti-CitJED and 70 $\mathrm{AU} / \mathrm{ml}$ for anti-HomoCitJED. These minimum concentrations were required to obtain a dose-dependent, reproducible inhibition. Anti-CitJED and anti-HomoCitJED were considered as cross-reactive if inhibition with the noncognate peptide was $\geq 50 \%$ at any inhibiting peptide concentration. Inhibition of anti-CitJED and anti-HomoCitJED antibodies was also performed using control peptides containing arginine or lysine, JED-Arg and JED-Lys, respectively. Inhibitions with JED-Arg and JED-Lys were performed once per sample.

Personal non-commercial use only. The Journal of Rheumatology Copyright @ 2018. All rights reserved. 
Statistical analysis. Graphpad Prism 6.0 software was used for data analysis. Fisher's exact test was used for comparison of categorical values. The Kruskal-Wallis test with Dunn multiple comparison was used to compare expression of anti-CitJED and anti-HomoCitJED in patients with RA to healthy subjects, and patients with SLE and PsA ( $p<0.005$ was considered significant). Correlation between anti-CitJED and anti-HomoCitJED expression was tested using Spearman correlation. Two-way ANOVA with Bonferroni correction was used for statistical analysis of inhibition experiments ( $\mathrm{p}<0.01$ was considered significant).

\section{RESULTS}

Occurrence of anti-CitJED and anti-HomoCitJED antibodies in patients with RA and healthy subjects, as well as patients with SLE or PSA. IgG antibodies reactive to CitJED and HomoCitJED were assessed in 137 patients with RA, 51 healthy subjects, 37 patients with SLE, and 37 patients with PsA. Anti-CitJED levels were significantly higher in patients with RA compared to other groups ( $<<0.0001$; Figure 1A). Anti-CitJED was expressed in 69/137 (50\%) of patients with RA; 54/69 (78\%) of these patients had anti-CitJED levels $>2$ times the cutoff. Anti-CitJED was detected in 2/51 (4\%) of healthy subjects and was not detected in patients with SLE or PsA. Anti-HomoCitJED was also detected at elevated levels in patients with RA compared to other groups ( $p<0.0001$; Figure 1B). Of the patients with RA, 78/137 $(57 \%)$ were positive for serum anti-HomoCitJED, with 49/78 $(63 \%)$ of these anti-HomoCitJED-positive RA patients having antibody levels $>2$ times the cutoff. In contrast, only $4 / 51(8 \%)$ of healthy subjects had low levels of anti-HomoCitJED. Anti-HomoCitJED was not found in PsA, but was detected in 1 patient with SLE with a concentration of 162.6 $\mathrm{AU} / \mathrm{ml}$. This patient with SLE was felt to have an overlap

a

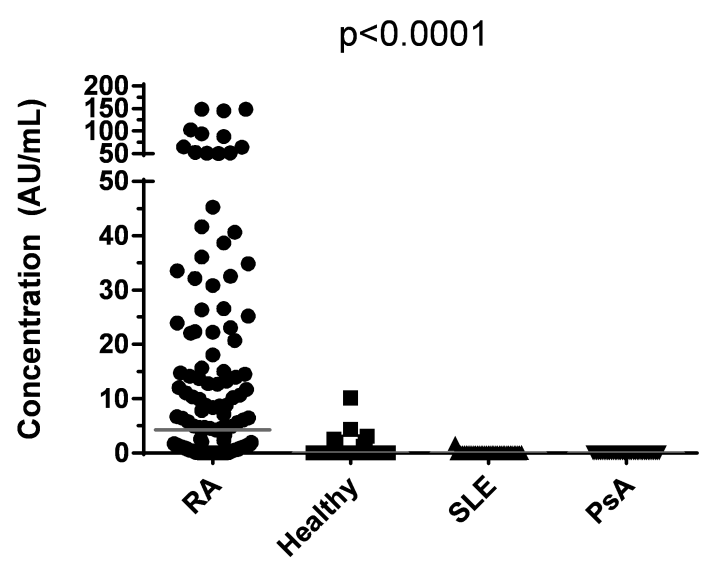
given that this patient had erosive inflammatory arthritis and was also anti-CCP2-positive. These results indicate that anti-CitJED and anti-HomoCitJED antibodies are frequently present at high concentrations in patients with RA, and infrequently found in healthy subjects, SLE, or PsA patients.

Coexpression of anti-CitJED and anti-HomoCitJED antibodies in patients with RA. Out of 137 patients with RA, $48(35 \%)$ were negative for both anti-CitJED and anti-HomoCitJED, while 58/137 (42\%) of patients with RA were positive for both antibodies. There were $11(8 \%)$ and $20(15 \%)$ patients with RA who were single positive for anti-CitJED or anti-HomoCitJED, respectively. Thus, anti-CitJED and anti-HomoCitJED have a concordance of $77 \%$. A strong correlation was found in the levels of serum anti-CitJED and anti-HomoCitJED [Spearman correlation coefficient $\left(\mathrm{r}_{\mathrm{s}}\right)=0.6676, \mathrm{p}<0.0001$; Figure 2] and we observed an association between anti-CitJED and anti-HomoCitJED antibody expression with OR 12.65 (95\% CI 5.52-29.00). The levels of anti-HomoCitJED in patients with anti-CitJED and anti-HomoCitJED were significantly greater compared to patients who had anti-HomoCitJED alone ( $\mathrm{p}<0.001$, data not shown).

The expression of anti-CitJED and anti-HomoCitJED in relation to anti-CCP2 is shown in Figure 3. Out of 137 patients with RA, 87 (64\%) were positive for anti-CCP2. Of the anti-CCP2-positive patients with RA, 53 (61\%) expressed anti-CitJED and 58 (67\%) were positive for anti-HomoCitJED. In the 50 patients with RA who lacked anti-CCP2, 16 (32\%) had anti-CitJED and $20(40 \%)$ had anti-HomoCitJED. Only b

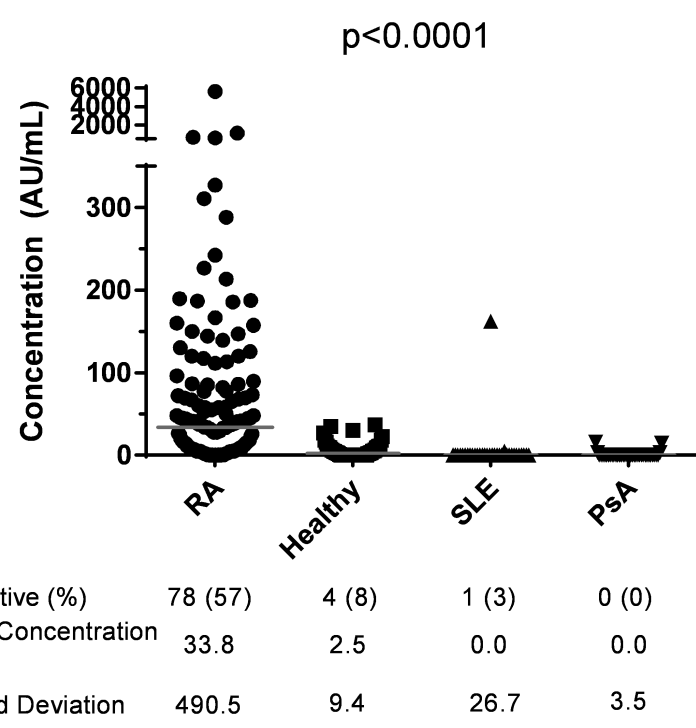

$\begin{array}{lcccc}\begin{array}{l}\text { No. Positive (\%) } \\ \text { Median Concentration }\end{array} & 78(57) & 4(8) & 1(3) & 0(0) \\ \begin{array}{l}\text { (AU/mL) } \\ \text { Standard Deviation }\end{array} & 490.5 & 2.5 & 0.0 & 0.0 \\ \end{array}$

\begin{tabular}{|c|c|c|c|c|}
\hline No. Positive (\%) & $69(50)$ & $2(4)$ & $0(0)$ & $0(0)$ \\
\hline $\begin{array}{l}\text { Median Concentration } \\
(\mathrm{AU} / \mathrm{mL})\end{array}$ & 4.2 & 0.0 & 0.0 & 0.0 \\
\hline Standard Deviation & 27.6 & 1.6 & 0.3 & 0.0 \\
\hline
\end{tabular}

Figure 1. Anti-CitJED and anti-HomoCitJED levels are increased in patients with RA. Serum anti-CitJED (A) and anti-HomoCitJED (B) were screened in patients with RA $(n=137)$, healthy subjects $(n=51)$, patients with SLE $(n=37)$, and patients with PsA ( $n=37)$. Cutoff values were 3.8 AU/ml for anti-CitJED and 25.3 AU/ml for anti-HomoCitJED. Grey bars represent the median concentration. Number and percentages of positive sera, SD, and median concentrations are shown below the respective group. RA: rheumatoid arthritis; SLE: systemic lupus erythematosus; PsA: psoriatic arthritis; AU: arbitrary units.

Personal non-commercial use only. The Journal of Rheumatology Copyright (C) 2018. All rights reserved. 


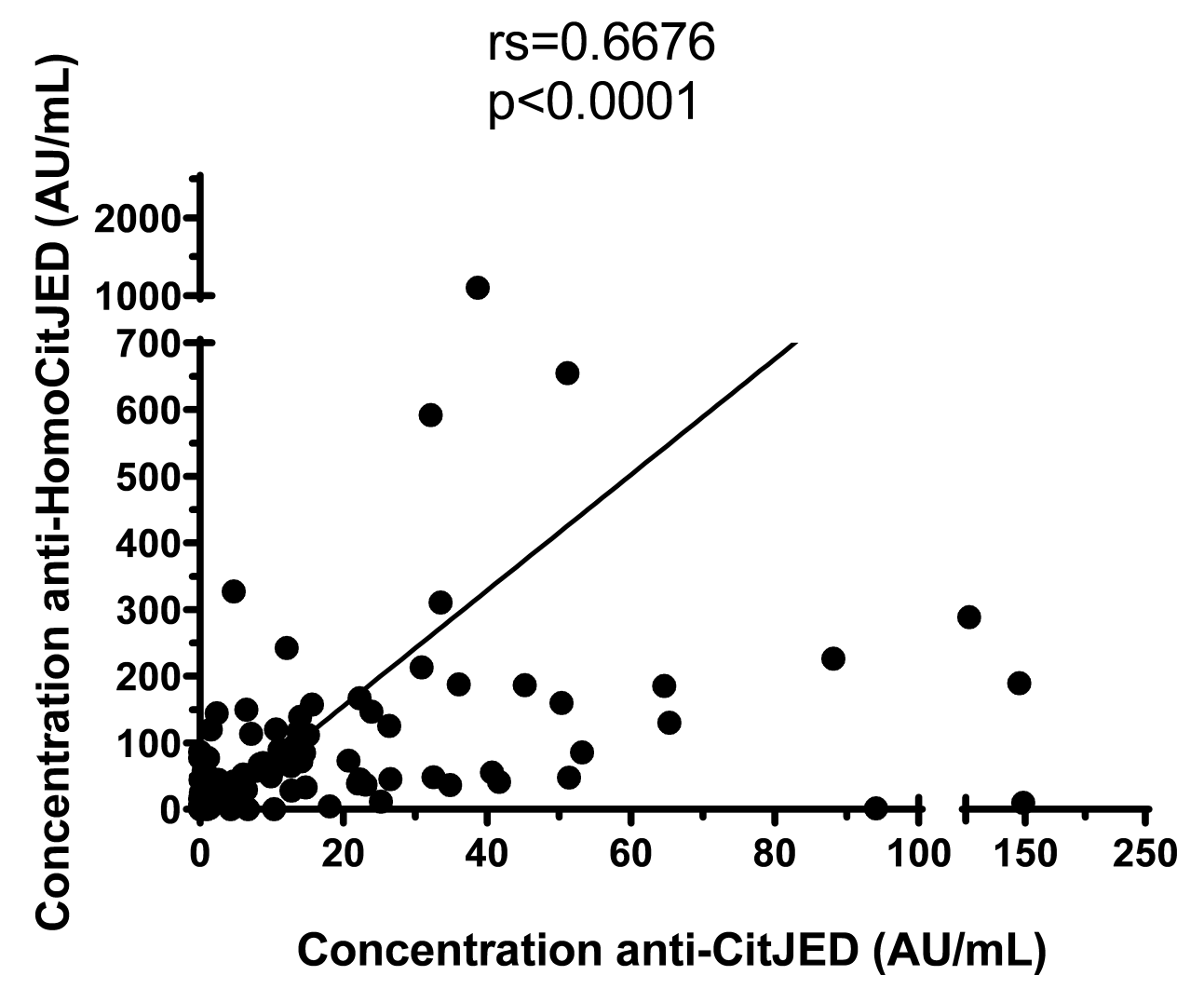

Figure 2. Anti-CitJED and anti-HomoCitJED levels are correlated in RA $(\mathrm{n}=137)$. The levels of anti-CitJED and anti-HomoCitJED antibodies were compared by Spearman nonparametric correlation. RA: rheumatoid arthritis; AU: arbitrary units.

A anti-CCP2 positive RA Patients $(n=87)$

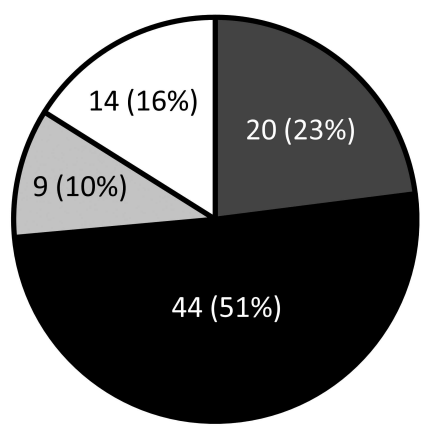

B anti-CCP2 negative RA Patients $(n=50)$

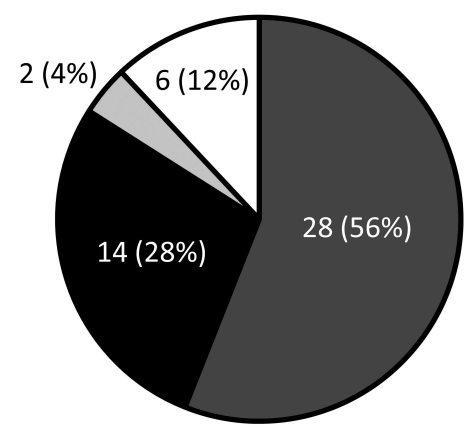

口CitJED-/ HomoCitJED-

DCitJED+/ HomoCitJED+

口CitJED+/ HomoCitJED-

口CitJED-/ HomoCitJED+

Figure 3. Anti-CitJED and anti-HomoCitJED are found in anti-CCP2-positive (A) and anti-CCP2-negative (B) patients with RA. Data shown are n (\%). RA: rheumatoid arthritis; anti-CCP: anticyclic citrullinated peptide antibodies.

6/137 (4\%) of patients with RA were positive for anti-HomoCitJED and negative for both anti-CitJED and anti-CCP2; only 1 of these patients had anti-HomoCitJED levels $>2$ times the cutoff. Of the 137 patients with RA, 36 $(26 \%)$ were negative for both anti-CCP2 and/or RF. In this latter subpopulation, $12 / 36(33 \%)$ of patients with RA expressed anti-CitJED and/or anti-HomoCitJED; 2/36 (6\%) expressed anti-CitJED only, 2/36 (6\%) expressed anti-HomoCitJED only, and 8 expressed both antibodies.

Cross-reactivity of anti-CitJED and anti-HomoCitJED antibodies. To examine the cross-reactivity of anti-CitJED and anti-HomoCitJED, we performed inhibition ELISA on 
RA sera (Figure 4), which met required anti-CitJED levels of $10 \mathrm{AU} / \mathrm{ml}$ and/or anti-HomoCitJED levels of $70 \mathrm{AU} / \mathrm{ml}$, as described. We examined 15 anti-CCP2-positive and 2 anti-CCP2-negative patients with RA who expressed both anti-CitJED and anti-HomoCitJED (referred to here as double positive; Figure 4A, B; Supplementary Figure 1, and Supplementary Figure 2, available with the online version of this article). We also examined 5 patients who were anti-CitJED-positive but anti-HomoCitJED-negative (anti-CitJED single positive; Figure 4C and Supplementary Figure 3), and 5 patients who were anti-HomoCitJEDpositive but anti-CitJED-negative (anti-HomoCitJED single positive; Figure 4D and Supplementary Figure 3). These single-positive patients were also positive for anti-CCP2 None of the sera from single-positive patients who were anti-CCP2-negative met the required antibody concentrations for the inhibition assay.

Anti-CitJED and anti-HomoCitJED from double-positive and single-positive patients with RA were inhibited by both
CitJED and HomoCitJED peptides (Figure 4). The binding affinity for CitJED and HomoCitJED peptides was examined by comparing the peptide concentrations of CitJED and HomoCitJED required to achieve 50\% inhibition of antibody reactivity. The cognate peptide produced significantly greater inhibition of antibody reactivity ( $p<0.0001$; Figure 4). In double-positive and anti-CitJED single-positive patients with RA, inhibition $>50 \%$ of anti-CitJED binding activity required $2 \mu \mathrm{g} / \mathrm{ml}$ of CitJED on average, compared to 100 $\mu \mathrm{g} / \mathrm{ml}$ of HomoCitJED (Figure 4A and Figure 4C). Anti-CitJED from 2/5 anti-CitJED single-positive patients showed little to no inhibition by HomoCitJED (Supplementary Figure 3). In double-positive patients with RA, inhibition of $50 \%$ of anti-HomoCitJED binding activity required $10 \mu \mathrm{g} / \mathrm{ml}$ of HomoCitJED compared to $50 \mu \mathrm{g} / \mathrm{ml}$ for CitJED (Figure 4B). In the group of anti-HomoCitJED single-positive patients, $50 \%$ inhibition of anti-HomoCitJED activity required $50 \mu \mathrm{g} / \mathrm{ml}$ of HomoCitJED compared to 100 $\mu \mathrm{g} / \mathrm{ml}$ of CitJED (Figure 4D). These results indicate that
A

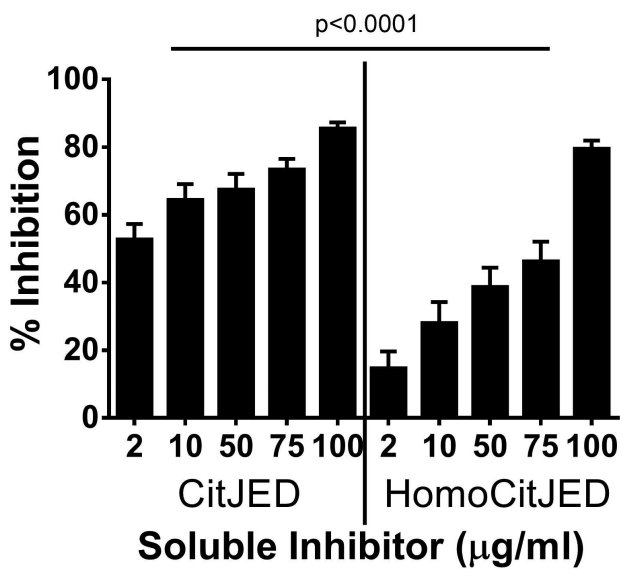

C

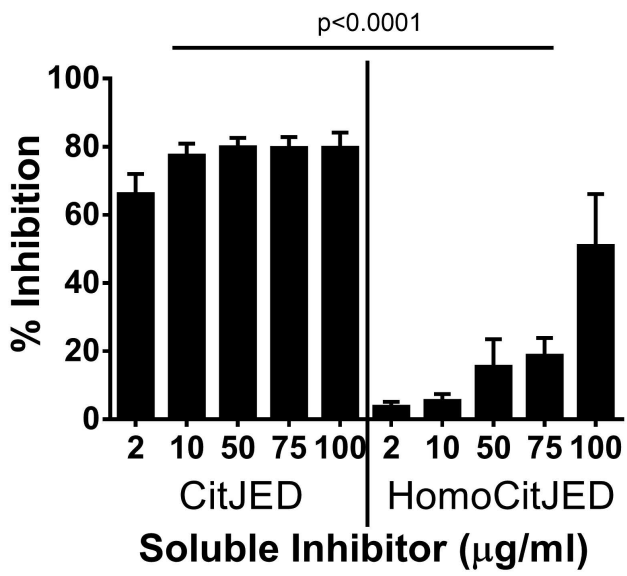

B

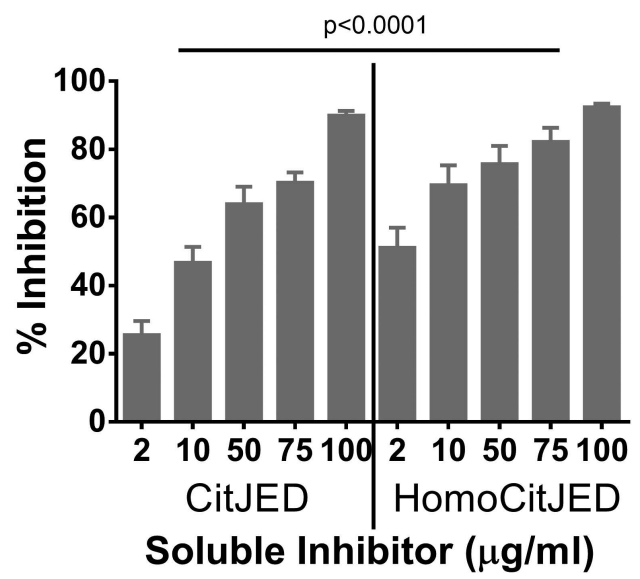

D

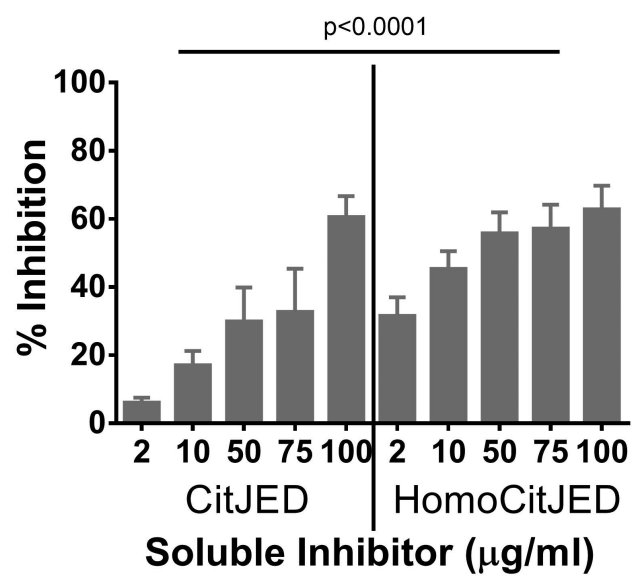

Figure 4. Anti-CitJED and anti-HomoCitJED from patients with RA are cross-reactive. Sera containing anti-CitJED (A, C) and anti-HomoCitJED (B, D) from patients with RA were inhibited with CitJED and HomoCitJED at the concentrations shown (average inhibitions \pm standard error are shown: $(\mathrm{A}, \mathrm{B}) \mathrm{n}=15$ for anti-CitJED and anti-HomoCitJED double positive; $(\mathrm{C}) \mathrm{n}=$ 5 for anti-CitJED single positive; and (D) $\mathrm{n}=5$ for anti-HomoCitJED single positive by direct ELISA. Inhibition was conducted at least twice for each serum. $\mathrm{p}<0.01$ was considered significant by 2-way ANOVA. RA: rheumatoid arthritis. 
anti-CitJED and anti-HomoCitJED antibodies are crossreactive, and have a higher inferred binding affinity to their respective cognate peptide. Sera from 5 patients with RA who expressed both anti-CitJED and anti-HomoCitJED were examined by inhibition with the control peptides, JED-Arg and JED-Lys. These peptides did not inhibit the binding activity of anti-CitJED and anti-HomoCitJED (data not shown).

\section{DISCUSSION}

In our study, we used synthetic citrullinated and homocitrullinated peptides, containing equal numbers of citrulline or homocitrulline residues, to examine the expression pattern and cross-reactivity of ACPA (represented by anti-CitJED) and AHCPA (represented by anti-HomoCitJED) in patients with RA. We found that antibodies reactive to CitJED and HomoCitJED were frequently expressed in the serum of patients with RA. These antibodies were rarely found in healthy individuals and in patients with SLE or PsA. The expression of anti-CitJED and anti-HomoCitJED antibodies was $77 \%$ concordant. Additionally, we have demonstrated that anti-CitJED and anti-HomoCitJED are frequently cross-reactive in the patients studied and have higher affinity for the cognate peptide.

We detected IgG anti-HomoCitJED antibodies in 57\% of patients with RA, a higher proportion than was reported for other antibodies targeting homocitrullinated proteins or peptides $(19-45 \%)^{8,17,18,19,25,26,27}$. Similarly, IgG anti-HomoCitJED was expressed in a significant proportion $(28 \%)$ of anti-CCP2/RF-negative patients with RA. Antibodies to homocitrullinated proteins and peptides have been previously reported in anti-CCP2-negative patients with RA to varying degrees $8,18,25,26,27$. This variability may be attributed to several factors, including differences in the characteristics of the study populations (genetics, environmental exposures, and disease activity). Consistent with a prior study, we did not observe a significant difference in IgG anti-HomoCitJED expression between RA patients with and without a history of smoking (data not shown) ${ }^{25}$. Our RA population had longer disease duration compared to the other studies and therefore may have developed more AHCPA reactivity over time. We have also found that $\operatorname{IgG}$ anti-HomoCitJED were rarely found in healthy individuals and patients with SLE or PsA. The specificity of $\operatorname{IgG}$ anti-HomoCitJED for RA requires further study with other types of inflammatory conditions. Some studies have identified antibodies to carbamylated fetal calf serum (anti-CarP) in other inflammatory arthritides and connective tissue diseases (in up to $50 \%$ of patients) $26,27,28,29,30$.

Prior studies did not examine the extent and affinity of antibody cross-reactivity of antibodies to citrullinated or homocitrullinated peptides, leading to the question of whether ACPA and AHCPA are part of a single antibody family or 2 separate antibody systems. We performed detailed inhibition experiments, allowing for analyses of the prevalence and affinity of cross-reactive ACPA and AHCPA. Using CitJED and HomoCitJED peptides that have equal numbers of citrulline and homocitrulline residues, respectively, we observed that anti-CitJED and anti-HomoCitJED antibodies were inhibited by both peptides in the majority of patients with RA ( $25 / 27$ of patients with RA examined by inhibition ELISA), including those who were positive for only 1 of these antibodies by direct ELISA. The difference in antibody peptide-binding activity observed between direct ELISA and inhibition ELISA could be caused by lower peptide concentrations used in direct ELISA, or possibly owing to conformational differences between soluble peptides and plate-bound peptides. These results suggest significant cross-reactivity between ACPA and AHCPA and support the notion that these antibodies are part of the same antibody family, as proposed by Reed, et $a l^{19}$. Cross-reactivity to citrullinated and homocitrullinated antigens has also been demonstrated in experimental animals. Turunen, et al showed that immunization with homocitrullinated antigens led to the development of anticitrulline reactivity in rabbits ${ }^{15}$. Further, Mydel, et al observed the development of erosive arthritis in mice, immunized with a homocitrullinated filaggrin peptide, followed by the introduction of citrullinated filaggrin peptide into the knee ${ }^{31}$.

In RA, it is not known whether citrullinated or homocitrullinated antigens (or both) are responsible for the initiation of autoantibody development. ACPA and AHCPA have been detected in patients years prior to disease onset ${ }^{6,10,11,32}$. Further, the anticitrullinated protein antibody response has been demonstrated to undergo epitope spreading, resulting in an expansion of the ACPA repertoire over time ${ }^{32}$. Because of the structural similarity between citrulline and homocitrulline, epitope spreading may lead to ACPA acquiring AHCPA specificities or vice versa. We observed that the degree of cross-reactivity varied among RA patients, with the majority having higher affinity for the cognate antigen. This finding likely reflects the abundance of the cognate antigen, which drives B cell maturation toward the production of higher-affinity antibodies to the same antigen. We identified 2 patients that did not have cross-reactive antibodies who were both anti-CitJED-positive; however, we did not determine whether these patients would later develop cross-reactivity to homocitrulline.

There are limitations to our study: measurements were performed at 1 timepoint, few patients had early disease, and samples from pre-RA subjects were not available. Future longitudinal studies of patients with early and pre-RA could provide a better understanding of the role of antihomocitrulline and anticitrulline antibodies in the initiation and progression of RA. Detailed clinical information was also not available; therefore, we could not assess the effect of the cross-reactivity and affinity of these antibodies on RA disease activity and severity.

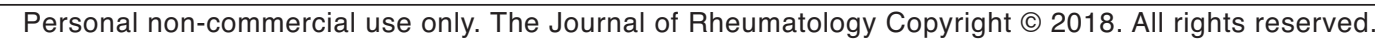


Antibodies to HomoCitJED and CitJED were frequently found in patients with RA and were rare in other conditions. These findings demonstrate the immunologic relatedness of ACPA and AHCPA as detected by assays using CitJED and HomoCitJED peptides with equal numbers of citrulline and homocitrulline residues, and suggest that these antibodies are potentially derived from the same B cell population. Cross-reactive $\mathrm{B}$ cells may provide a mechanism by which AHCPA are involved in RA pathogenesis.

\section{ACKNOWLEDGMENT}

We thank Sheri Saunders for technical assistance, and Dr. Sherry Rohekar, Dr. Dafna D. Gladman, and Dr. Janet Pope for providing PsA and SLE sera

\section{ONLINE SUPPLEMENT}

Supplementary material accompanies the online version of this article.

\section{REFERENCES}

1. Schellekens GA, de Jong BA, van den Hoogen FH, van de Putte LB, van Venrooij WJ. Citrulline is an essential constituent of antigenic determinants recognized by rheumatoid arthritis-specific autoantibodies. J Clin Invest 1998;101:273-81.

2. Schellekens GA, Visser H, de Jong BA, van den Hoogen FH, Hazes $\mathrm{JM}$, Breedveld FC, et al. The diagnostic properties of rheumatoid arthritis antibodies recognizing a cyclic citrullinated peptide. Arthritis Rheum 2000;43:155-63.

3. Goldbach-Mansky R, Lee J, McCoy A, Hoxworth J, Yarboro C, Smolen JS, et al. Rheumatoid arthritis associated autoantibodies in patients with synovitis of recent onset. Arthritis Research 2000;2:236-43.

4. Hill JA, Al-Bishri J, Gladman DD, Cairns E, Bell DA. Serum autoantibodies that bind citrullinated fibrinogen are frequently found in patients with rheumatoid arthritis. J Rheumatol 2006;33:2115-9.

5. Scinocca M, Bell DA, Racapé M, Joseph R, Shaw G, McCormick $\mathrm{JK}$, et al. Antihomocitrullinated fibrinogen antibodies are specific to rheumatoid arthritis and frequently bind citrullinated proteins/peptides. J Rheumatol 2014;41:270-9.

6. Shi J, van de Stadt LA, Levarht EW, Huizinga TW, Hamann D, van Schaardenburg D, et al. Anti-carbamylated protein (anti-CarP) antibodies precede the onset of rheumatoid arthritis. Ann Rheum Dis 2014;73:780-3.

7. Shi J, van de Stadt LA, Levarht EW, Huizinga TW, Toes RE, Trouw LA, et al. Anti-carbamylated protein antibodies are present in arthralgia patients and predict the development of rheumatoid arthritis. Arthritis Rheum 2013;65:911-5.

8. Shi J, Knevel R, Suwannalai P, van der Linden MP, Janssen GM, van Veelen PA, et al. Autoantibodies recognizing carbamylated proteins are present in sera of patients with rheumatoid arthritis and predict joint damage. Proc Natl Acad Sci U S A 2011;108:17372-7.

9. Bell DA, Elhayek S, Cairns E, Barra L. Anti-homocitrullinated protein antibody isotype usage in rheumatoid arthritis and their unaffected first-degree relatives. Clin Exp Rheumatol 2017 Jun 5 (E-pub ahead of print).

10. Nielen MM, van Schaardenburg D, Reesink HW, van de Stadt RJ, van der Horst-Bruinsma IE, de Koning MH, et al. Specific autoantibodies precede the symptoms of rheumatoid arthritis: A study of serial measurements in blood donors. Arthritis Rheum 2004;50:380-6.

11. Avouac J, Gossec L, Dougados M. Diagnostic and predictive value of anti-cyclic citrullinated protein antibodies in rheumatoid arthritis: a systematic literature review. Ann Rheum Dis 2006;65:845-51.
12. Kastbom A, Strandberg G, Lindroos A, Skogh T. Anti-CCP antibody test predicts the disease course during 3 years in early rheumatoid arthritis (the Swedish TIRA project). Ann Rheum Dis 2004;63:1085-9.

13. Petkova SB, Konstantinov KN, Sproule TJ, Lyons BL, Awwami MA, Roopenian DC. Human antibodies induce arthritis in mice deficient in the low-affinity inhibitory IgG receptor Fc gamma RIIB. J Exp Med 2006;203:275-80.

14. Brintnell W, Bell DA, Cairns E. The mechanisms underlying arthritogenicity of human anticitrulline antibodies [abstract]. Arthritis Rheum 2009;58:S433.

15. Turunen S, Koivula MK, Risteli L, Risteli J. Anticitrulline antibodies can be caused by homocitrulline-containing proteins in rabbits. Arthritis Rheum 2010;62:3345-52.

16. Shi J, Willemze A, Janssen GM, van Veelen PA, Drijfhout JW, Cerami A, et al. Recognition of citrullinated and carbamylated proteins by human antibodies: specificity, cross-reactivity and the "AMC-Senshu" method. Ann Rheum Dis 2013;72:148-50.

17. Turunen S, Hannonen P, Koivula MK, Risteli L, Risteli J. Separate and overlapping specificities in rheumatoid arthritis antibodies binding to citrulline- and homocitrulline-containing peptides related to type I and II collagen telopeptides. Arthritis Res Ther 2015;17:2 .

18. Juarez M, Bang H, Hammar F, Reimer U, Dyke B, Sahbudin I, et al. Identification of novel antiacetylated vimentin antibodies in patients with early inflammatory arthritis. Ann Rheum Dis 2016;75:1099-107.

19. Reed E, Jiang X, Kharlamova N, Ytterberg AJ, Catrina AI, Israelsson $\mathrm{L}$, et al. Antibodies to carbamylated $\alpha$-enolase epitopes in rheumatoid arthritis also bind citrullinated epitopes and are largely indistinct from anti-citrullinated protein antibodies. Arthritis Res Ther 2016;18:96.

20. Aletaha D, Neogi T, Silman AJ, Funovits J, Felson DT, Bingham CO 3rd, et al. 2010 Rheumatoid arthritis classification criteria: An American College of Rheumatology/European League Against Rheumatism collaborative initiative. Arthritis Rheum 2010;62:2569-81.

21. Hochberg MC. Updating the American College of Rheumatology revised criteria for the classification of systemic lupus erythematosus. Arthritis Rheum 1997;40:1725.

22. Taylor W, Gladman D, Helliwell P, Marchesoni A, Mease P, Mielants H; CASPAR Study Group. Classification criteria for psoriatic arthritis: Development of new criteria from a large international study. Arthritis Rheum 2006;54:2665-73.

23. Ercan A, Cui J, Chatterton DE, Deane KD, Hazen MM, Brintnell W, et al. Aberrant IgG galactosylation precedes disease onset, correlates with disease activity, and is prevalent in autoantibodies in rheumatoid arthritis. Arthritis Rheum 2010;62:2239-48.

24. Hill JA, Cairns E, Bell DA, inventors. Peptides associated with MHC class II molecules involved in autoimmune diseases. United States full patent application (US10/548258) filed 2004 Mar 5; published 2007 Dec 20. Canadian full patent application (CA2518187) filed 2005 Sept 20. Patent Treaty Cooperation Application (WO 04/078098) filed 2004 Mar 5 to secure worldwide protection. Europe (EP1603937) published 2005 Dec 14. Japan (JP2007524583) published 2007 Aug 30. Australia (AU4216925) issued 2010 .

25. Jiang X, Trouw LA, van Wesemael TJ, Shi J, Bengtsson C, Källberg $\mathrm{H}$, et al. Anti-CarP antibodies in two large cohorts of patients with rheumatoid arthritis and their relationship to genetic risk factors, cigarette smoking and other autoantibodies. Ann Rheum Dis 2014:1761-8.

26. Pecani A, Alessandri C, Spinelli FR, Priori R, Riccieri V, Di Franco $\mathrm{M}$, et al. Prevalence, sensitivity and specificity of antibodies against carbamylated proteins in a monocentric cohort of patients with rheumatoid arthritis and other autoimmune rheumatic diseases. Arthritis Res Ther 2016;18:276. 
27. Nakabo S, Yoshifuji H, Hashimoto M, Imura Y, Nakashima R, Murakami K, et al. Anti-carbamylated protein antibodies are detectable in various connective tissue diseases. J Rheumatol 2017;44:1384-8.

28. Shi J, van Steenbergen HW, van Nies JA, Levarht EW, Huizinga TW, van der Helm-van Mil AH, et al. The specificity of anti-carbamylated protein antibodies for rheumatoid arthritis in a setting of early arthritis. Arthritis Res Ther 2015;17:339.

29. Ziegelasch M, van Delft MA, Wallin P, Skogh T, Magro-Checa C, Steup-Beekman GM, et al. Antibodies against carbamylated proteins and cyclic citrullinated peptides in systemic lupus erythematosus: results from two well-defined European cohorts. Arthritis Res Ther 2016;18:289.
30. Bergum B, Koro C, Delaleu N, Solheim M, Hellvard A, Binder V, et al. Antibodies against carbamylated proteins are present in primary Sjögren's syndrome and are associated with disease severity. Ann Rheum Dis 2016;75:1494-500.

31. Mydel P, Wang Z, Brisslert M, Hellvard A, Dahlberg LE, Hazen SL, et al. Carbamylation-dependent activation of $\mathrm{T}$ cells: a novel mechanism in the pathogenesis of autoimmune arthritis. J Immunol 2010;184:6882-90.

32. Van der Woude D, Rantapaa-Dahlqvist S, Ioan-Facsinay A, Onnekink C, Schwarte CM, Verpoort KN, et al. Epitope spreading of the anti-citrullinated protein antibody response occurs before disease onset and is associated with the disease course of early arthritis. Ann Rheum Dis 2010;69:1554-61. 